\title{
Does the type of suturing technique used affect astigmatism after deep anterior lamellar keratoplasty in keratoconus patients?
}

This article was published in the following Dove Press journal:

Clinical Ophthalmology

3I March 20I I

Number of times this article has been viewed

\author{
Banu Torun Acar \\ Ece Turan Vural \\ Suphi Acar \\ Haydarpasa Numune Education and \\ Research Hospital, Ophthalmology \\ Clinic, Istanbul, Turkey
}

Correspondence: Banu Torun Acar Ophthalmologist, Tibbiye Caddesi Haydarpasa Numune Egitim ve Arastırma Hastanesi, No. 4034668 Uskudar. Istanbul, Turkey

Tel +90505 5l89682

Fax +902163377877

Email torunbanu@yahoo.com
Purpose: To compare the effect of three different suturing techniques on astigmatism after deep anterior lamellar keratoplasty (DALK) in patients with keratoconus.

Methods: In this retrospective study, 54 eyes of 54 patients with advanced keratoconus underwent DALK with three suturing techniques: single running, interrupted running, and combined interrupted and running. Postkeratoplasty astigmatism was evaluated during examinations 1, 3, and 6 months postoperatively and 2 months after completing suture removal.

Results: Twenty-four eyes had single running sutures, 16 eyes had interrupted sutures, and in 14 eyes the suturing technique used was combined interrupted and running sutures. Mean age was $25.6 \pm 5.9$ years, $27.3 \pm 6.8$ years, and $26.5 \pm 5.7$ years $(P=0.422)$, and postoperative astigmatism 1 month after surgery was $3.79 \pm 1.19 \mathrm{D}, 5.56 \pm 1.78 \mathrm{D}$, and $4.21 \pm 1.55 \mathrm{D}$ in the three groups, respectively $(P=0.012)$. However, 2 months after completing the suture removal, final postoperative astigmatism was $3.43 \pm 1.44 \mathrm{D}, 3.87 \pm 1.38 \mathrm{D}$, and $3.71 \pm 1.46 \mathrm{D}$ $(P=0.846)$. Final astigmatism less than $4 \mathrm{D}$ was seen in 18 cases $(75 \%)$ in the single running group, nine cases $(56.2 \%)$ in the interrupted running group, and nine cases $(64.2 \%)$ in the combined interrupted and running group $(P=0.08)$.

Conclusion: Postkeratoplasty astigmatism is comparable with three different suturing techniques used in patients with keratoconus after completing suture removal in DALK. Due to earlier suture removal in DALK, the type of suturing technique used is not considerably important.

Keywords: astigmatism, deep anterior lamellar keratoplasty, suturing technique

\section{Introduction}

As with penetrating keratoplasty (PK), visual acuity (VA) depends on graft clarity and refractive error in deep anterior lamellar keratoplasty (DALK). Despite a clear graft, high astigmatism may not achieve the desired level of increase in visual acuity. ${ }^{1}$ Causes of postoperative astigmatism are donor button-recipient bed disparity, ${ }^{2,3}$ trephine size ${ }^{2,4}$ recipient pathology, ${ }^{1}$ malposition of donor and recipient tissues, ${ }^{5}$ decentralized trephination, ${ }^{6}$ suture technique, ${ }^{7-10}$ and time of suture removal. ${ }^{11-13}$

There are a variety of suture techniques, such as single running (SR), double running (DR), interrupted running (IR), and combined interrupted and running (CIR). Several studies prove that the SR suture technique results in lower astigmatism than the IR or CIR suture techniques. , $^{7,14,15}$

Published clinical studies conducted thus far have compared the suturing techniques in PK. To the best of our knowledge, this study is the first study comparing the suture techniques in patients with keratoconus who underwent DALK. In this randomized clinical trial we aimed to assess the impact of three different suturing techniques on astigmatism in keratoconus patients after DALK. 


\section{Materials and methods}

This randomized clinical trial was performed on 54 eyes of 54 patients with keratoconus who underwent DALK between March 2008 and May 2010 at Haydarpasa Numune Education and Research Hospital, Istanbul, Turkey. All the protocols of our study were concordant with the tenets of the Declaration of Helsinki, and informed consent was obtained from all patients. Patients included in this study were contact lens intolerant and/or had best contact lens-corrected VA less than 20/80. Patients with anterior or posterior segment disorders such as glaucoma, lens dislocation, retinitis pigmentosa, degenerative myopia, corneal neovascularizations, vernal keratokonjunctivitis, regrafts, and return to PK due to Descemet membrane perforation were excluded from the study.

DALK was performed by using Anwar and Teichmann's ${ }^{16}$ big-bubble technique with the same surgeon. The recipient cornea was trephined (to a depth of approximately $60 \%-80 \%$ ) according to recipient corneal size (range 7.0-7.5 mm). The donor cornea without Descemet membrane and endothelium was trephined from the stromal surface by Hessburg-Barron suction trephine (JedMed Instrument Co., St Louis, MO). For all patients, 10-0 nylon suture material was applied. The donor cornea was initially secured in the recipient bed with four cardinal sutures at the $12,6,3$, and 9 o'clock positions. In the first group of patients, a 16-bite 10-0 nylon SR suture was placed. The second group of patients received 16 separate IR sutures, and the other eight separate bites were accompanied by a row of 16-bite continuous sutures using the CIR suturing technique. The four cardinal sutures had been removed before the SR sutures were tightened. In the IR and CIR suturing techniques, the four cardinal sutures were renewed. At the end of the surgery, in order to minimize postoperative astigmatism, an evaluation of corneal sphericity was perfomed using a Maloney handheld keratoscope (Storz, St Louis, MO). Subconjunctival $20 \mathrm{mg}$ of gentamicin and $4 \mathrm{mg}$ of betamethasone were injected at the end of surgery.

Postoperatively, patients received topical ciprofloxacin $0.3 \%$ and prednisolone acetate $1 \%$ four times daily and preservative-free artificial tears every 2 hours in the first month, which were subsequently tapered over the next 6 months.

Follow-up examinations were performed at 1, 3, and 6 months postoperatively. Furthermore, corresponding examinations were repeated after 2 months, completing the suture removal process. All patients were examined with keratometry (Charops, Mirae Optics Co. Ltd., Kyonggi-Do, Korea) and a corneal topography system (Magellan Mapper, Nidek Technologies, Padova, Italy). According to the keratometry and topography in eyes with more than $4 \mathrm{D}$ of astigmatism, suture adjustment was performed 4 to 8 weeks postoperatively in the SR group, and selective sutures were removed at least 2 months postoperatively in the steep meridian in the IR and CIR groups.

Data were analyzed with SPSS 16.0 software (SPSS, Inc., Chicago, IL). One-way analysis of variance (ANOVA) was used for quantitative parameters among three groups. A $P$ value of $<0.05$ was considered statistically significant. The $X^{2}$ test was applied for comparison of qualitative parameters.

\section{Results}

Twenty-four eyes were treated with the SR suture technique, 16 eyes with the IR suture technique, and 14 eyes with the CIR suture technique. Mean age was $25.6 \pm 5.9$ years, $27.3 \pm 6.8$ years, and $26.5 \pm 5.7$ years in the three groups, respectively (ANOVA, $P=0.422$ ). Degree of keratoconus was similar in all groups $(P=0.438)$. The mean trephine size of the recipient was $7.30 \pm 0.28 \mathrm{~mm}, 7.20 \pm 0.22 \mathrm{~mm}$, and $7.26 \pm 0.24 \mathrm{~mm}$ for the SR, IR, and CIR groups, respectively, and these differences were not statistically significant $(P=0.638)$. The mean trephine size of the donor was $7.72 \pm 0.26 \mathrm{~mm}, 7.64 \pm 0.20 \mathrm{~mm}$, and $7.70 \pm 0.22 \mathrm{~mm}$ for the SR, IR, and CIR groups, respectively, and these differences were not statistically significant $(P=0.630)$. The mean donor recipient disparity was $0.42 \pm 0.12 \mathrm{~mm}, 0.44 \pm 0.08 \mathrm{~mm}$, and $0.44 \pm 0.11 \mathrm{~mm}$ for the SR, IR, and CIR groups, respectively, and these were not significantly different $(P=0.824)$. Preoperative and intraoperative variables in each suturing technique group are summarized in Table 1 .

One month after the surgery, which was before the suture adjustment, postoperative astigmatism was higher in the IR suture group than in the other groups (ANOVA, $P=0.012$; Table 2). There was no difference in astigmatism between the groups in the follow-up period after the suture adjustment (Table 2). Sutures were removed on the fixed schedule for all groups. There were no complications after suture removal. The mean suture removal time was $5.8 \pm 0.9$ months in the SR group, $5.9 \pm 0.75$ months in the IR group, and $5.84 \pm 0.82$ months in the CIR group. There was no significant difference between the three groups $(P=0.896)$. At the last follow-up visit, 2 months after suture removal, the mean astigmatism was $3.43 \pm 1.44 \mathrm{D}$ in the SR suture group, $3.87 \pm 1.38 \mathrm{D}$ in the IR suture group, and $3.71 \pm 1.46 \mathrm{D}$ in the CIR group. In the SR suture group, mean astigmatism measured by keratometry had decreased more than in the other groups, but the difference was not statistically significant (ANOVA, $P=0.846$; Table 2; Figure 1). Although in the SR suture group 18 eyes $(75 \%)$ had a mean astigmatism 
Table I Preoperative and intraoperative variables in each suturing technique

\begin{tabular}{|c|c|c|c|c|}
\hline & \multicolumn{4}{|c|}{ Suture techniques } \\
\hline & SR & IR & CIR & $P$ value ${ }^{a}$ \\
\hline Number of eyes & 24 & 16 & 14 & \\
\hline Mean age (year) & $25.6 \pm 5.9$ & $27.3 \pm 6.8$ & $26.5 \pm 5.7$ & 0.422 \\
\hline Recipient trephine size (mm) & $7.30 \pm 0.28$ & $7.20 \pm 0.22$ & $7.26 \pm 0.24$ & 0.638 \\
\hline Donor trephine size $(\mathrm{mm})$ & $7.72 \pm 0.26$ & $7.64 \pm 0.20$ & $7.70 \pm 0.22$ & 0.630 \\
\hline Donor-recipient disparity (mm) & $0.42 \pm 0.12$ & $0.44 \pm 0.08$ & $0.44 \pm 0.11$ & 0.824 \\
\hline Mean suture removal time (month) & $5.8 \pm 0.9$ & $5.9 \pm 0.75$ & $5.84 \pm 0.82$ & 0.896 \\
\hline Degree of keratoconus (topographic keratometry) & $61.62 \pm 5.09$ & $62.10 \pm 6.70$ & $60.48 \pm 4.20$ & 0.438 \\
\hline
\end{tabular}

Note: a One-way analysis of variance; no significiant difference between the three groups.

Abbreviations: $\mathrm{CIR}$, combined interrupted and single running; IR, interrupted running; SR, single running.

less than $4 \mathrm{D}$, nine eyes (56\%) in the IR suture group and nine eyes (64.2\%) in the CIR suture group had an astigmatism less than $4 \mathrm{D}\left(X^{2}, P=0.08\right)$. At the last follow-up visit, the best VA was $0.76 \pm 0.09,0.74 \pm 0.08$, and $0.75 \pm 0.1$ in the SR, IR, and CIR groups, respectively $(P=0.583)$.

\section{Discussion}

This study was conducted to investigate postoperative astigmatism after DALK by using different suturing techniques. In earlier studies, suturing techniques were compared after conducting PK. In reference to the literature, this study is the first randomized clinical trial that has compared suture techniques after DALK.

Similar to PK, recipient pathology, ${ }^{1}$ donor buttonrecipient bed disparity, ${ }^{2,3}$ trephine size, ${ }^{2,4}$ malposition of donor and recipient tissues, ${ }^{5}$ decentralized trephination, ${ }^{6}$ suture technique, ${ }^{7-10}$ and time of suture removal ${ }^{11-13}$ are factors that affect postoperative astigmatism in DALK.

Javadi et $a{ }^{17}$ studied 103 keratoconus patients who had undergone PK with the three different suturing techniques (IR, SR, and CIR). They reported that the three different suturing techniques were comparable after suture removal in keratoconus patients. In this study, the diagnosis of all patients was keratoconus. No significant difference was found in astigmatism between the three suturing techniques.

In a prospective study, Lin et a $1^{10}$ compared two groups: SR technique and suture adjustment after surgery, and DR technique and no adjustment. They reported that in the SR group astigmatism was significantly less in respect of the inital state 4 months after the surgery.

Shimazaki et al ${ }^{18}$ evaluated the role of suture adjustment with SR suturing at three different time intervals. They found that earlier suture adjustment is more effective on final astigmatism.

Spadea et $a{ }^{13}$ reported that there was no significant change of astigmatism after suture removal, whereas Solano et a ${ }^{19}$ reported that astigmatism increased 1 month after suture removal in the SR group. In this study, there was no difference of astigmatism after suture removal in all groups.

Van Meter et $\mathrm{al}^{8}$ compared two suturing techniques for PK: SR and CIR. They concluded that the SR suture technique may offer less postoperative astigmatism and earlier optical stability.

McNeil and Aaen ${ }^{12}$ reported that postoperative suture adjustment of SR suturing significantly decreases astigmatism after suture removal in PK.

Karabatsas et $\mathrm{a}^{20}$ performed a randomized prospective study comparing two suturing techniques (SR and IR), and they reported no significant difference between SR group with suture adjustment and IR group with selective suture removal.

Kim et al ${ }^{1}$ compared the effects of three different suturing techniques (SR, IR, and DR) on post-PK astigmatism. They found that in the DR group postkeratoplasty astigmatism was the least. In their study, the number of keratoconus patients

Table 2 Postkeratoplasty astigmatism at follow-up intervals

\begin{tabular}{|c|c|c|c|c|}
\hline Postoperative follow-up & SR & IR & CIR & $P$ value \\
\hline Astigmatism I month after surgery & $3.79 \pm 1.19$ & $5.56 \pm 1.78$ & $4.21 \pm 1.55$ & $0.012^{\mathrm{a}, \mathrm{b}}$ \\
\hline Astigmatism 3 months after surgery & $3.70 \pm 1.35$ & $3.96 \pm 1.8$ & $3.80 \pm 1.64$ & $0.587^{a}$ \\
\hline Astigmatism 6 months after surgery & $3.56 \pm 1.52$ & $3.82 \pm 1.72$ & $3.75 \pm 1.56$ & $0.762^{\mathrm{a}}$ \\
\hline Astigmatism 2 months after suture removal & $3.43 \pm 1.44$ & $3.87 \pm 1.38$ & $3.71 \pm 1.46$ & $0.846^{\mathrm{a}}$ \\
\hline Patients final astigmatism $<4 \mathrm{D}$ & $18(75 \%)$ & $9(56.25 \%)$ & $9(64.3 \%)$ & $0.08^{c}$ \\
\hline
\end{tabular}

Note: a One-way analysis of variance; bstatistically significant difference; ' $X{ }^{2}$ test.

Abbreviations: $\mathrm{CIR}$, combined interrupted and single running; IR, interrupted running; SR, single running. 


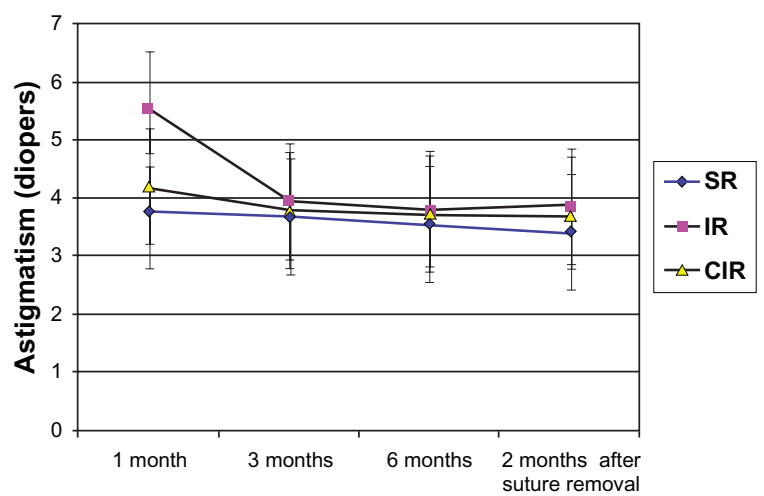

Figure I Changes in astigmatism at I, 3, and 6 months and 2 months after suture removal after deep anterior lamellar keratoplasty in three groups.

was lower in the IR group than in the other two groups. In this study we have included only keratoconus patients, and there was no significant difference between the three groups after DALK.

The most important advantage of DALK over PK is earlier suture removal. In PK, sutures are removed at least 1 year after surgery, whereas, in DALK, suture removal time is approximately 6 months after surgery. In this study, DALK was performed in keratoconus patients, and the outcomes of this randomized clinical trial indicate that the three suturing techniques (SR, IR, and CIR) are comparable in terms of postoperative astigmatism.

In conclusion, because of the earlier suture removal in DALK, the type of suturing technique used does not have a critical role for controlling postkeratoplasty astigmatism.

\section{Disclosure}

There was no public or private financial support for this paper. None of the authors has a financial or proprietary interest in any product, method, or material used in the study. This study was presented at the 28th Congress of the European Society of Cataract and Refractive Surgeons; September 4-8, 2010; Paris, France.

\section{References}

1. Kim SJ, Wee WR, Lee JH, Kim MK. The effect of different suturing techniques on astigmatism after penetrating keratoplasty. $J$ Korean Med Sci. 2008;23:1015-1019.

Clinical Ophthalmology

\section{Publish your work in this journal}

Clinical Ophthalmology is an international, peer-reviewed journal covering all subspecialties within ophthalmology. Key topics include: Optometry; Visual science; Pharmacology and drug therapy in eye diseases; Basic Sciences; Primary and Secondary eye care; Patient Safety and Quality of Care Improvements. This journal is indexed on
2. Perl T, Charlton KH, Binder PS. Disparate diameter grafting. Astigmatism, intraocular pressure, and visual acuity. Ophthalmology. 1981:88:774-781

3. Seitz B, Langenbucher A, Küchle M, Naumann GO. Impact of graft diameter on corneal power and the regularity of postkeratoplasty astigmatism before and after suture removal. Ophthalmology. 2003;110:2162-2167.

4. Insler MS, Cooper HD, Caldwell DR. Final surgical results with a suction trephine. Ophthalmic Surg. 1987;18:23-27.

5. Hoppenreijs VP, Van Rij G, Beekhuis WH, et al. Causes of high astigmatism after penetrating keratoplasty. Doc Ophthalmol. 1993;85:21-34.

6. Cohen KL, Holman RE, Tripoli NK, Kupper LL. Effect of trephine tilt on corneal button dimensions. Am J Ophthalmol. 1986;101:722-725.

7. Boruchoff SA, Jensen AD, Dohlman CH. Comparison of suturing techniques in keratoplasty for keratoconus. Ann Ophthalmol. 1975;7: 433-436.

8. Van Meter WS, Gussler JR, Soloman KD, Wood TO. Postkeratoplasty astigmatism control. Single continuous suture adjustment versus selective interrupted suture removal. Ophthalmology. 1991;98:177-183.

9. Murta JN, Amaro L, Tavares C, Mira JB. Astigmatism after penetrating keratoplasty. Role of the suture technique. Doc Ophthalmol. 1994;87: 331-336.

10. Lin DT, Wilson SE, Reidy JJ, et al. An adjustable single running suture technique to reduce postkeratoplasty astigmatism. A preliminary report. Ophthalmology. 1990;97:934-938.

11. Musch DC, Meyer RF, Sugar A. The effect of removing running sutures on astigmatism after penetrating keratoplasty. Arch Ophthalmol. 1988; 106:488-492.

12. McNeill JI, Aaen VJ. Long-term results of single continuous suture adjustment to reduce penetrating keratoplasty astigmatism. Cornea. 1999;18:19-24.

13. Spadea L, Cifariello F, Bianco G, Balestrazzi E. Long-term results of penetrating keratoplasty using a single or double running suture technique. Graefes Arch Clin Exp Ophthalmol. 2002;240:415-419.

14. Filatov V, Steinert RF, Talamo JH. Post keratoplasty astigmatism with single running suture or interrupted sutures. Am J Ophthalmol. 1993;115:715-721.

15. Eliason JA, McCulley JP. A comparison between interrupted and continuous suturing techniques in keratoplasty. Cornea. 1990;9:10-16.

16. Anwar M, Teichmann KD. Deep lamellar keratoplasty: surgical technique for anterior lamellar keratoplasty with and without baring of Descemet's membrane. Cornea. 2002;21:374-383.

17. Javadi MA, Naderi M, Zare M, et al. Comparison of the effect of three suturing techniques on postkeratoplasty astigmatism in keratoconus. Cornea. 2006;25:1029-1033.

18. Shimazaki J, Shimmura S, Tsubota K. Intraoperative versus postoperative suture adjustment after penetrating keratoplasty. Cornea. 1998;17: 590-594.

19. Solano JM, Hodge DO, Bourne WM. Keratometric astigmatism after suture removal in penetrating keratoplasty: double running versus single running suture techniques. Cornea. 2003;22:716-720.

20. Karabatsas $\mathrm{CH}$, Cook SD, Figueiredo FC, et al. Combined interrupted and continuous versus single continuous adjustable suturing in penetrating keratoplasty: a prospective, randomized study of induced astigmatism during the first postoperative year. Ophthalmology. 1998;100: 119-127.

\section{Dovepress}

PubMed Central and CAS, and is the official journal of The Society of Clinical Ophthalmology (SCO). The manuscript management system is completely online and includes a very quick and fair peer-review system, which is all easy to use. Visit http://www.dovepress.com/ testimonials.php to read real quotes from published authors. 